\title{
PENGARUH PERSEPSI AGEN BRILINK TERHADAP KEPUTUSAN PENGGUNAAN LAYANAN BRANCHLESS BANKING
}

\section{THE EFFECT OF AGENT BRILINK PERCEPTION ON THE DECISION TO USE BRANCHLESS BANKING SERVICE}

\author{
Riza Rahmanu*)1, Lilik Noor Yuliati**), dan Bunasor Sanim***) \\ ${ }^{*}$ PT Bank Rakyat Indonesia (Persero), Tbk \\ Jl. Boulevard Barat Blok LC 6 Kav 69-70, Kelapa Gading, Jakarta Utara, Indonesia \\ ${ }^{* *}$ Departemen Ilmu Konsumen dan Kelurga, Fakultas Ekologi Manusia, IPB University \\ J1. Darmaga, Kampus IPB Dramaga, Bogor 16680, Indonesia \\ ${ }^{* * * *}$ Sekolah Bisnis, IPB University \\ J1. Pajajaran Bogor 16151, Indonesia
}

\begin{abstract}
This study aims to analyze the influence of Brilink Agents Perception on the decision to use BRI branchless banking service through the AIDA model. The research method is carried out by modeling the Structural Equation Model (SEM) regarding the relationship between brilink agent perceptions of the relative advantage, risk, trust, usefulness, and security as well as the agent's perception of awareness, interest, desire and action. Data collection techniques were carried out by distributing questionnaires to the community around Brilink agents by cluster random sampling. From these results it can be seen that for the brilink agent user model variables that have a dominant influence are trust, security, usefulness, risk, and relative advantage. As for the non-brilink agent model, the most dominant variables are risk, security, trust, relative advantage and usefulness. The results of using SEM also found that the influence of Brilink Agent's perception of the AIDA variable (awareness, interest, desire, and action) had a greater indirect effect, that is, the brilink Agent's perception variable affected awareness then awareness affected interest, desire, and then action. In addition to knowing the effectiveness of brilink agents, a customer response index value is calculated with the results of the Customer Response Index value at each stage having a value above the minimum value so that it can be said that the brilink agent has a good effectiveness.
\end{abstract}

Keywords: branchless banking, customer response index, structural equation model, AIDA

\begin{abstract}
Abstrak: Penelitian ini bertujuan untuk menganalisis pengaruh persepsi Agen brilink terhadap keputusan penggunaan layanan Branchless Banking BRI. Metode penelitian dilakukan dengan pemodelan Structural Equation Model (SEM) mengenai hubungan antara persepsi agen brilink terhadap relative advantage, risk, trust, usefullness, dan security serta persepsi agen brilink terhadap awareness, interest, desire dan action. Teknik pengumpulan data dilakukan dengan cara membagikan kuisioner kepada masyarakat di sekitar agen brilink dengan cara cluster random sampling. Dari hasil ini dapat dilihat bahwa untuk model pengguna agen brilink variabel yang memiliki pengaruh dominan adalah trust, security, usefullness, risk, dan relative advantage. Sedangkan untuk model bukan pengguna agen brilink variabel yang paling dominan adalah risk, security, trust, relative advantage dan usefullness. Hasil menggunakan SEM juga ditemukan bahwa pengaruh persepsi Agen brilink terhadap variabel AIDA (awareness, interest, desire, dan action) lebih besar pengaruhnya secara tidak langsung, yaitu variabel persepsi Agen brilink berpengaruh terhadap awareness kemudian awareness mempengaruhi interest, desire, kemudian action. Selain itu untuk mengetahui efektifitas agen brilink, dilakukan perhitungan nilai customer response index dengan hasil nilai Customer Response Index di setiap tahapan memiliki nilai di atas nilai minimum sehingga dapat dikatakan Agen brilink memiliki efektifitas yang baik sebagai agen Branchless Banking BRI.
\end{abstract}

Kata kunci: branchless banking, customer response index, structural equation model. AIDA

\footnotetext{
${ }^{1}$ Alamat Korespondensi:

Email: rahmanuriza@gmail.com
} 


\section{PENDAHULUAN}

Perkembangan industri perbankan di Indonesia berkembang pesat dalam beberapa tahun terakhir, dari tahun 2015 sampai dengan tahun 2019 asset industri perbankan tumbuh 41\% (SPI, 2019). Namun, perkembangan industri perbankan di Indonesia masih fokus kepada masyarakat perkotaan, isu yang berkembang dalam bisnis perbankan adalah pelayanan perbankan yang masih bersifat ekslusif, karena belum dapat dirasakan oleh seluruh masyarakat, terutama masyarakat yang berdomisili jauh dari bank. Di Indonesia baru $36 \%$ penduduknya yang memiliki rekening atau akses ke sektor keuangan (Bank Indonesia, 2015).

Akses terhadap layanan perbankan menjadi bagian yang penting pada pertumbuhan ekonomi dan pengentasan kemiskinan. Sistem inklusi keuangan yang baik dapat membantu kaum miskin untuk memperbaiki taraf hidupnya sehingga mereka pun dapat menikmati layanan perbankan sebagai fasilitas yang mendukung kehidupan mereka sehari-hari (Steelyana, 2013).

Bagi industri perbankan, sulit untuk memberikan pelayanan bagi masyarakat yang jauh dari Bank, karena membutuhkan overhead cost yang tinggi seperti biaya pembangunan kantor, biaya gaji karyawan, dan biaya operasional lainnya. Posisi Juli 2019 tingkat BOPO perbankan di Indonesia sebesar 81,08\% (SPI, 2019).

Otoritas Jasa Keuangan sebagai regulator yang mengatur kebijakan perbankan memahami isu tersebut dan mengeluarkan ketentuan Branchless Banking Laku Pandai (Layanan Keuangan Tanpa Kantor Dalam Rangka Keuangan Inklusif) pada bulan November 2014 melalui POJK No. 19/POJK.03/2014, yang dimana ketentuan ini memberikan kelonggaran kepada perbankan untuk dapat melayani masyarakat yang berdomisili jauh dari bank tanpa harus mendirikan kantor (Branchless Banking). Bank dapat bekerjasama dengan Agen yang telah ditunjuk oleh bank untuk dapat melayani masyarakat dengan layanan laku pandai. layanan laku pandai terdiri dari tabungan basic saving account, kredit mikro, dan produk keuangan lainnya seperti asuransi mikro.

Perkembangan laku pandai di Indonesia sangat cepat, hal ini dapat dilihat dari pertumbuhan agen laku pandai dari 3.734 agen pada Juni 2015 menjadi 160.490 agen pada September 2016. Selain itu, jangkauan wilayah agen laku pandai yang sebelumnya 211 Kota/Kabupaten posisi Juni 2015 menjadi 499 Kota/ Kabupaten posisi september 2016. Hal ini menandakan bahwa agen Branchless Banking (laku pandai) sudah menjangkau ke pelosok negeri untuk dapat melayani transaksi keuangan perbankan (http://www.ojk.go.id/ id/Pages/Laku-Pandai.aspx). Layanan branchless banking merupakan solusi untuk meningkatkan inklusi keuangan khususnya bagi masyarakat di daerah terpencil yang sulit dijangkau oleh jaringan Cabang Perbankan (Purwati, 2014).

Berdasarkan regulasi yang dikeluarkan oleh OJK tersebut, industri perbankan Indonesia menanggapi dengan positif dan melihat hal ini sebagai potensi bisnis, industri perbankan dapat melayani masyarakat yang jauh dari bank tanpa harus mendirikan kantor cabang. Salah satu contohnya adalah Bank BRI yang pada Posisi April 2017 sudah memiliki 100.311 agen Branchless Banking yang dinamakan agen brilink dengan total transaksi 220 Miliar Rupiah. Namun, dari total agen brilinkyang ada hanya 66.344 agen yang aktif dalam melakukan transaksi.

Rofiq (2015) meneliti mengenai pengaruh penerapan teori AIDA dalam keputusan pembelian Kartu Perdana IM3 di Universitas Brawijaya Malang. Hasil penelitian tersebut menunjukkan bahwa variabel awareness, interest, desire, dan action berpengaruh dalamkeputusan pembelian mahasiswa. Sakti (2014) meneliti mengenai Pengaruh Tahapan AIDA pada Iklan Rokok Terhadap Keputusan Pembelian. Hasil penelitian menunjukkan variabel Awareness, Interest, Desire dan action berpengaruh dalam keputusan pembelian konsumen terhadap rokok, sehingga dapat dikatakan bahwa iklan rokok tersebut effektif dalam memengaruhi keputusan pembelian konsumen. Penelitian yang dilakukan oleh Ayuningtyas (2014) yang berjudul "Analisis Pengaruh Kompetensi Tenaga Penjual Daya Tarik Promosi dan Citra Perusahaan Terhadap Keputusan Pembelian Produk Asuransi Jiwa" dapat dibuktikan bahwa Variabel kompetensi tenaga penjual berpengaruh kepada keputusan pembelian produk asuransi jiwa. Berdasarkan penelitian tersebut penulis tertarik untuk melakukan analisis Pengaruh kinerja agen brilink terhadap keputusan penggunaan layanan branchless banking Bank BRI dengan menggunakan pendekatan Teori AIDA. Teori AIDA digunakan untuk melihat keefektifan agen brilink dalam pengambilan keputusan 
layanan branchless banking BRI. Beberapa faktor persepsi yang dinilai di agen brilink adalah (relative advantage, risk, trust, usefullness dan security).

Perbedaan penelitian ini dengan penelitian terdahulu adalah penelitian ini melihat pengaruh faktor apa saja diantara relative advantage, risk, trust, usefullness dan security yang paling dominan memengaruhi keputusan penggunaan layanan branchless banking BRI, sehingga dapat menghasilkan rekomendasi untuk dapat mengedepankan faktor tersebut agar dapat meningkatkan transaksi di agen brilink. Selain itu juga peneliti menggunakan pendekatan teori AIDA dengan cara mengukur melalui customer response index.

Peran agen brilink sebagai agen branchless banking BRI sangat besar mengingat, dengan perkembangan teknologi Bank akan fokus pada efisiensi. Agen brilink akan dijadikan sebagai perpanjangan tangan BRI karena cukup efisien dalam pengelolaannya. Namun, BRI perlu melihat faktor apa saja yang sangat dominan bagi masyarakat untuk melakukan transaksi melalui Agen Brilink, sehingga BRI dapat lebih focus dalam strateginya untuk meningkatkan transaksi keuangan melalui Agen brilink. Adapun beberapa faktor yang peneliti masukan dalam model adalah relative advantage, risk, trust, usefullness dan security. Selain itu selain faktor-faktor tersebut, diperlukan juga pembanding yang dapat mengukur keefektifan agen brilink selama ini sebagai agen branchless banking Bank BRI.

Tujuan penelitian adalah untuk mengetahui pengaruh agen brilink terhadap keputusan penggunaan layanan branchless banking bank BRI dengan menggunakan pendekatan Teori AIDA beberapa faktor yang dinilai di agen brilink tersebut antara lain relative advantage, risk, trust, usefullness dan security) dan pengaruhnya terhadap keputusan penggunaan layanan agen brilink yang dinilai dari awareness, interest, desire dan action nasabah Bank BRI. Serta menganalisis efektifitas agen brilink sebagai agen Branchless Banking Bank BRI dengan menggunakan model perhitungan Customer Respon Index.

\section{METODE PENELITIAN}

Data yang diperlukan untuk penelitian ini diambil dari dua sumber yaitu: data primer dan data sekunder. Data primer diperoleh dengan cara melakukan wawancara langsung terhadap responden dengan mengajukan beberapa pertanyaan melalui kuesioner. Responden dalam penelitian ini adalah nasabah BRI yang sudah menggunakan layanan agen branchless banking dan nasabah BRI yang belum menggunakan Layanan agen branchless banking.

Data sekunder, didapat oleh penulis secara tidak langsung melalui media perantara (internet dan website perusahaan) atau diperoleh dari pihak lain. Data sekunder digunakan untuk mendukung data primer dari internal kantor maupun instansi terkait, yaitu berupa dokumen atau catatan dari laporan keuangan, dan sumber link website.

Jumlah responden yang digunakan dalam penelitian ini adalah 180 Responden yang sudah menggunakan layanan agen branchless banking BRI dan 160 responden yang belum pernah menggunakan layanan agen branchless banking BRI. Sehingga total responden sejumlah 340 Responden. Teknik pengambilan data dengan cara cluster random sampling. Responden adalah nasabah BRI yang berdomisili dekat dengan agen brilink atau sering melintasi lokasi agen brilink.

Penelitian ini mengunakan data primer yang dengan metode wawancara dengan alat bantu berupa kuesioner yang berisi sejumlah pertanyaan tertulis yang terstruktur guna memperoleh informasi yang akurat dari responden tentang persepsi agen brilink. Kuesioner adalah alat untuk mengumpulkan data primer, Pertanyaan dalam kuesioner dilakukan dengan skala Likert. Metode pengisian kuesioner dilakukan dengan manual menggunakan kertas kuesioner. Responden yang mengisi kuesioner dibagi menjadi 2 tipe, yaitu 1) Nasabah BRI yang sudah menggunakan layanan agen Brilink. Pembagian Kuesioner dilakukan dengan cara mendatangi agen brilink dan memberikan kuesioner kepada nasabah BRI yang menggunakan layanan agen brilink; 2) Nasabah yang sudah mengetahui layanan agen brilink namun belum menggunakan Layanan tersebut. Pembagian kuesioner dilakukan dengan cara mendatangi agen brilinkdan membagikan kuesioner kepada nasabah BRI di sekitar agen brilink yang mengetahui layanan agen brilink namun belum menggunakan layanan agen brilik.

Model penelitian yang digunakan dalam penelitian ini adalah model struktur berjenjang dan untuk menguji hipotesis yang diajukan digunakan teknik analisis SEM (Structural Equation Modelling) yang dioperasikan 
melalui program Linear Structural Relationship (LISREL).

Untuk menyatakan kejelasan dari beberapa variabel yang akan diteliti dalam penelitian ini, maka diperlukan batasan atau definisi secara operasional untuk tiap variabel yang akan digunakan. Sugiyono (2009) mengemukakan definisi operasional variabel pada dasarnya adalah segala sesuatu yang berbentuk apa saja yang ditetapkan oleh peneliti untuk dipelajari sehingga diperoleh informasi tentang hal tersebut, kemudian ditarik kesimpulannya. SEM baik yang berbasis covariance maupun variance membagi konstruk menjadi dua, yaitu konstruk eksogen, dikenal sebagai "source variables" atau variabel independen yang tidak diprediksi oleh variabel yang lain dalam model.
Konstruk eksogen adalah konstruk yang dituju oleh garis dengan satu ujung anak panah. Dalam penelitian ini, variabel eksogennya adalah Persepsi Agen Branchless Banking Bank BRI. Selanjutnya, konstruk endogen, adalah faktor-faktor yang diprediksi oleh satu atau beberapa konstruk. Konstruk endogen dapat memprediksi satu atau beberapa konstruk endogen yang lain. Ini berbeda dengan konstruk eksogen yang hanya dapat berhubungan kausal dengan konstruk endogen. Dalam penelitan ini, konstruk endogennya adalah Awareness (X1), Interest (X2), Desire (X3),Action (X4), Relative Advantage (X5), Risk (X6), Trust (X7), Usefullness (X8) dan Security (X9). Dari operasional variabel, maka dapat dilakukan rancangan model struktural, model pengukuran dan diagram jalur seperti pada Gambar 1 dan Gambar 2.

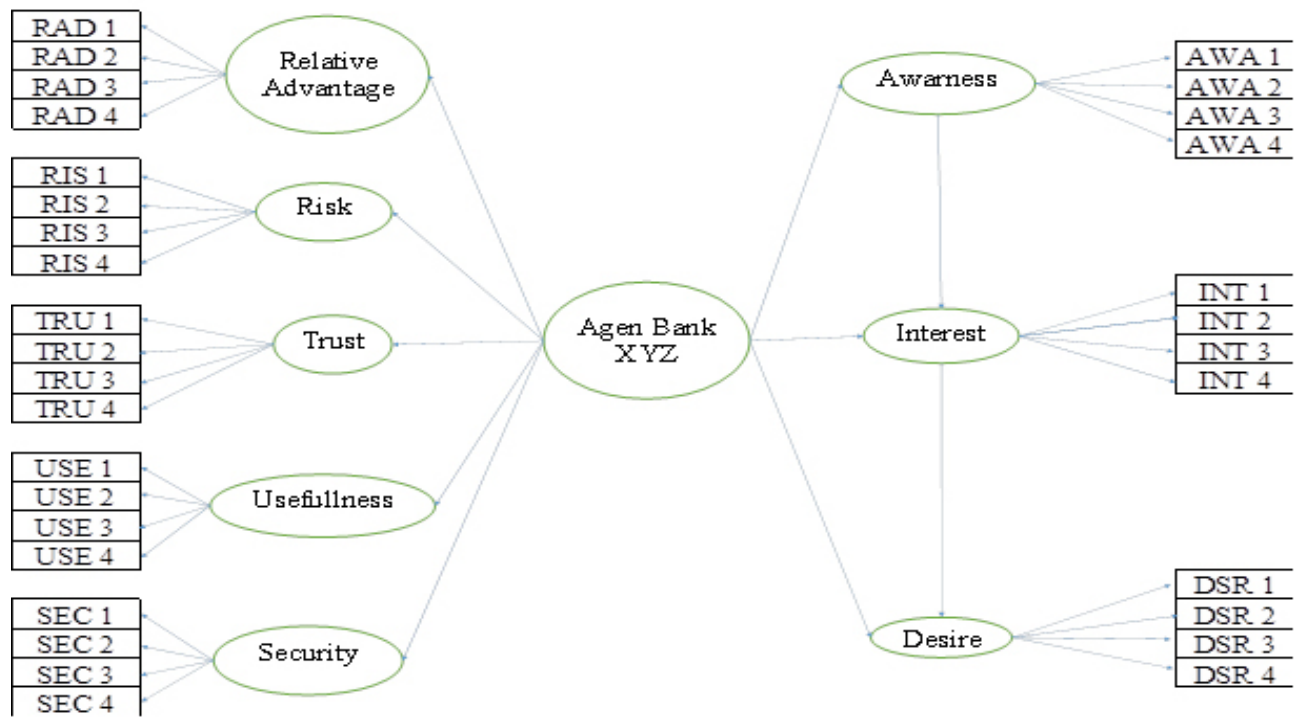

Gambar 1. Model SEM untuk nasabah yang sudah menggunakan layanan Brilink

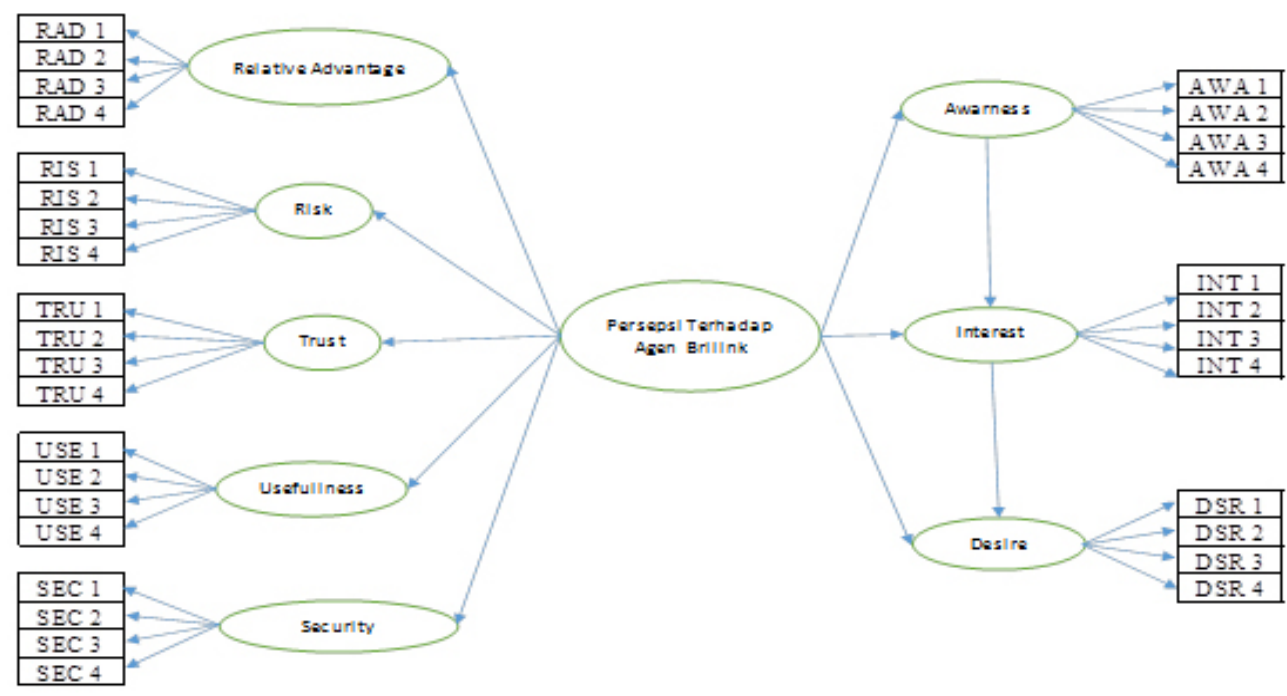

Gambar 2. Model SEM untuk nasabah yang belum menggunakan layanan Brilink 
Pada Gambar 3 dapat dilihat bahwa terdapat beberapa faktor yang dapat menilai persepsi dari Agen Branchless Banking Bank BRI yaitu, relative advantage, risk, trust, usefullness dan security. Faktor-faktor tersebut pada akhirnya akan berpengaruh terhadap awareness, interest, desire dan action masyarakat untuk menggunakan layanan transaksi financial melalui Agen Branchless Banking. Hipotesis penelitian ini sebagai berikut:

\section{Model pengguna agen Brilink}

H1 Pengaruh persepsi agen brilinksignifikant terhadap Relative Advantage

H2 Pengaruh persepsi agen brilinksignifikant terhadap Risk

H3 Pengaruh persepsi agen brilinksignifikant terhadap Trust

H4 Pengaruh Persepsi agen brilinksignifikant terhadap Usefullness

H5 Pengaruh persepsi agen brilinksignifikant terhadap Security

H6 Pengaruh persepsi agen brilinksignifikant terhadap Awareness

H7 Pengaruh persepsi agen brilinksignifikant terhadap Interest

H8 Pengaruh persepsi agen brilinksignifikant terhadap Desire

H9 Pengaruh persepsi agen brilinksignifikant terhadap action

H10 Pengaruh Awareness signifikant terhadap Interest

H11 Pengaruh Interest signifikan terhadap Desire

H12 Pengaruh Desire signifikan terhadap action

Model bukan pengguna agen Brilink

H1 Pengaruh persepsi agen brilinksignifikant terhadap Relative Advantage

H2 Pengaruh persepsi agen brilinksignifikant terhadap Risk

H3 Pengaruh persepsi agen brilinksignifikant terhadap Trust

H4 Pengaruh persepsi agen brilinksignifikant terhadap Usefullness

H5 Pengaruh persepsi agen brilinksignifikant terhadap Security

H6 Pengaruh persepsi agen brilinksignifikant terhadap Awareness

H7 Pengaruh persepsi agen brilinksignifikant terhadap Interest

H8 Pengaruh persepsi agen brilinksignifikant terhadap Desire
H9 Pengaruh persepsi agen brilinksignifikant terhadap action

H10 Pengaruh Awareness signifikant terhadap Interest

H11 Pengaruh Interest signifikant terhadap Desire

\section{HASIL}

\section{Uji Model Pengukuran dari Model Bukan Pengguna Agen Brilink}

Hipotesis H1: Persepsi terhadap Brilink berpengaruh significant terhadap Relative Advantage

Hipotesis pertama menguji pengaruh persepsi terhadap Brilink terhadap relative advantage dapat menjelaskan hasil berdasarkan Tabel nilai koefisien pengaruh atau loading factor sebesar 0,87 dengan thitung 24,42. Nilai mutlak t hitung lebih besar dari $t$ tabel dengan alpha 5\% sebesar 1,96. Artinya, persepsi terhadap Brilink berpengaruh significant dan positif terhadap relative advantage (Hipotesis diterima). Hal ini menunjukkan bahwa relative advantage berpengaruh terhadap minat menggunakan layanan Brilink.

Hipotesis H2: Persepsi terhadap Brilink berpengaruh significant terhadap Trust

Hipotesis kedua menguji pengaruh persepsi terhadap Brilink terhadap Trust dapat menjelaskan hasil berdasarkan Tabel nilai koefisien pengaruh atau loading factor sebesar 0,89 dengan $t$ hitung 18,48. Nilai mutlak t hitung lebih besar dari t tabel dengan alpha 5\% sebesar 1,96. Artinya, persepsi Terhadap Brilink berpengaruh significant dan positif terhadap trust (Hipotesis diterima). Hal ini menunjukkan bahwa trust berpengaruh terhadap minat menggunakan layanan Brilink. Dalam hal ini, dapat disimpulkan bahwa dalam melakukan transaksi keuangan nasabah BRI harus percaya bahwa agen brilink adalah benarbenar perpanjangan tangan dari Bank BRI.

Hipotesis H3: Persepsi terhadap Brilink berpengaruh significant terhadap Risk

Hipotesis ketiga menguji pengaruh persepsi terhadap Brilink terhadap Risk dapat menjelaskan hasil berdasarkan Tabel nilai koefisien pengaruh atau loading factor sebesar 0,93 dengan $t$ hitung 20,59. Nilai mutlak t hitung lebih besar dari t tabel dengan 
alpha 5\% sebesar 1,96. Artinya, persepsi terhadap brilink berpengaruh significant dan positif terhadap risk. (Hipotesis diterima) Hal ini menunjukkan bahwa risk berpengaruh terhadap minat menggunakan layanan Brilink.

Hipotesis H4: Persepsi terhadap Brilink berpengaruh significant terhadap Usefullness

Hipotesis keempat menguji pengaruh Persepsi Terhadap Brilink terhadap Usefullness dapat menjelaskan hasil berdasarkan Tabel nilai koefisien pengaruh atau loading factor sebesar 0,83 dengan t hitung 22,38. Nilai mutlak t hitung lebih besar dari t tabel dengan alpha $5 \%$ sebesar 1,96 artinya persepsi terhadap Brilink berpengaruh significant dan positif terhadap usefullness. (Hipotesis diterima) Hal ini menunjukkan bahwa usefullness berpengaruh terhadap minat menggunakan layanan Brilink. Dalam hal ini dapat disimpulkan bahwa usefullness agen brilink, yang tentunya tidak bisa dilakukan Bank, seperti jam pelayanan yang tidak terbatas (tergantung agen brilink), lokasi yang dekat dengan domisili nasabah Bank BRI membuat persepsi nasabah BRI terhadap agen brilink adalah layanan branchless banking yang bermanfaat bagi mereka, sehingga faktor tersebut akan meningkatkan minat penggunaan layanan agen brilink.

Hipotesis H5 : Persepsi terhadap Brilink berpengaruh significant terhadap security

Hipotesis kelima menguji pengaruh persepsi terhadap Brilink terhadap security dapat menjelaskan hasil berdasarkan Tabel nilai koefisien pengaruh atau loading factor sebesar 0,90 dengan thitung 22,63. Nilai mutlak $\mathrm{t}$ hitung lebih besar dari t tabel dengan alpha 5\% sebesar 1,96 artinya persepsi terhadap Brilink berpengaruh significant dan positif terhadap security. (Hipotesis diterima) Hal ini menunjukkan bahwa security berpengaruh terhadap minat menggunakan layanan Brilink. Dalam hal ini keamanan agen brilink dalam melakukan transaksi keuangan akan meningkatkan minat nasabah BRI untuk menggunakan layanan branchless banking.

Hipotesis H6: Persepsi terhadap Brilink berpengaruh significant dan positif terhadap Awareness

Hipotesis keenam menguji pengaruh persepsi terhadap Brilink terhadap awareness dapat menjelaskan hasil berdasarkan Tabel nilai koefisien pengaruh atau loading factor sebesar 0,81 dengan thitung 22,55. Nilai mutlak thitung lebih besar dari t tabel dengan alpha $5 \%$ sebesar 1,96 artinya Persepsi Terhadap Brilink berpengaruh significant dan positif terhadap awareness.(Hipotesis diterima) Hal ini menunjukkan bahwa persepsi terhadap Brilink dengan baik maka akan meningkatkan awareness terhadap produk BRILINK.

Hipotesis $\mathrm{H} 7$ : Persepsi terhadap Brilink berpengaruh tidak significant dan positif terhadap interest pada taraf nyata $5 \%$, namun significant pada taraf nyata $10 \%$.

Hipotesis ketujuh menguji pengaruh persepsi terhadap Brilink terhadap interest dapat menjelaskan hasil berdasarkan Tabel nilai koefisien pengaruh atau loading factor sebesar 0,22 dengan thitung 1,87 . Nilai mutlak t hitung lebih besar dari t tabel dengan alpha $10 \%$ sebesar 1,64 artinya persepsi terhadap Brilink berpengaruh significant dan positif terhadap interest. (Hipotesis diterima) Hal ini menunjukkan Persepsi Terhadap Brilink dengan baik maka akan meningkatkan interest terhadap produk BRILINK.

Hipotesis H8 : Persepsi terhadap Brilink berpengaruh significant dan positif terhadap desire

Hipotesis kedelapan menguji pengaruh Persepsi terhadap Brilink terhadap desire dapat menjelaskan hasil berdasarkan Tabel nilai koefisien pengaruh atau loading factor 0,30 dengan thitung 2,86 . Nilai mutlak $t$ hitung lebih besar dari t tabel dengan alpha 5\% sebesar 1,96 artinya persepsi terhadap Brilink berpengaruh significant terhadap desire. (Hipotesis diterima) Hal ini menunjukkan bahwa Persepsi Terhadap Brilink dengan baik maka memengaruhi langsung desire produk Brilink.

Hipotesis H9: Awareness berhubungan significant dan positif terhadap interest

Hipotesis kesembilan menguji hubungan awareness terhadap interest dapat menjelaskan hasil berdasarkan Tabel nilai koefisien hubungan atau loading factor sebesar 0,65 dengan $t$ hitung 4,03. Nilai mutlak $t$ hitung lebih besar dari $t$ tabel dengan alpha 5\% sebesar 1,96 artinya awareness berhubungan significant dan positif terhadap interest. (Hipotesis diterima) Hal ini menunjukkan bahwa tingkat awareness nya sudah baik maka akan meningkatkan interest terhadap produk Brilink.

Hipotesis H10 : Interest berhubungan significant dan 
positif terhadap desire

Hipotesis kesepuluh menguji hubungan interest terhadap desire dapat menjelaskan hasil berdasarkan Tabel 20 nilai koefisien hubungan atau loading factor sebesar 0,69 dengan $t$ hitung 4,81 . Nilai mutlak t hitung lebih besar dari t tabel dengan alpha 5\% sebesar 1,96 artinya interest berhubungan significant dan positif terhadap interest.(Hipotesis diterima) Hal ini menunjukkan bahwa tingkat interest nya sudah baik maka akan tidak langsung meningkatkan desire terhadap produk Brilink. Hasil hipotesa Model Bukan Pengguna Agen Brilink disimpulkan pada Tabel 3. Pada Tabel 4 dapat dilihat bahwa semua nilai GOFI menunjukkan kecocokan yang baik, sehingga dapat disimpulkan bahwa kecocokan data dan model adalah baik.

\section{Uji Model Pengukuran dari Model Pengguna Agen Brilink}

Hipotesis H1: Persepsi terhadap Brilink berpengaruh significant terhadap Relative Advantage

Hipotesis pertama menguji pengaruh Persepsi Terhadap Brilink terhadap relative advantage dapat menjelaskan hasil berdasarkan Tabel nilai koefisien pengaruh atau loading factor sebesar 0,72 dengan t hitung 11,36. Nilai mutlak t hitung lebih besar dari t tabel dengan alpha 5\% sebesar 1,96 artinya persepsi terhadap Brilink berpengaruh significant dan positif terhadap relative advantage. (Hipotesis diterima) Hal ini menunjukkan bahwa relative advantage berpengaruh terhadap minat menggunakan layanan Brilink.

Hipotesis H2: Persepsi terhadap Brilink berpengaruh significant terhadap Trust

Hipotesis kedua menguji pengaruh Persepsi Terhadap Brilink terhadap Trust dapat menjelaskan hasil berdasarkan Tabel nilai koefisien pengaruh atau loading factor sebesar 0,94 dengan thitung 18,81. Nilai mutlak $\mathrm{t}$ hitung lebih besar dari $\mathrm{t}$ tabel dengan alpha 5\% sebesar 1,96 artinya Persepsi Terhadap Brilink berpengaruh significant dan positif terhadap trust. (Hipotesis diterima) Hal ini menunjukkan bahwa trust berpengaruh terhadap minat menggunakan layanan Brilink.

Hipotesis H3: Persepsi terhadap Brilink berpengaruh significant terhadap Risk

Hipotesis ketiga menguji pengaruh Persepsi Terhadap Brilink terhadap Risk dapat menjelaskan hasil berdasarkan Tabel 5 nilai koefisien pengaruh atau loading factor sebesar 0,88 dengan t hitung 21,29. Nilai mutlak $\mathrm{t}$ hitung lebih besar dari $\mathrm{t}$ tabel dengan alpha 5\% sebesar 1,96 artinya persepsi terhadap Brilink berpengaruh significant dan positif terhadap risk. (Hipotesis diterima) Hal ini menunjukkan bahwa risk berpengaruh terhadap minat menggunakan layanan Brilink.

Tabel 3. Uji hipotesis model bukan pengguna agen Brilink

\begin{tabular}{lllcc}
\hline Hipotesis & & SLF & T Hitung & Kesimpulan \\
\hline $\mathrm{H} 1$ & Brilink $\rightarrow$ Relative Advantage & 0,87 & 24,42 & Significant \\
$\mathrm{H} 2$ & Brilink $\rightarrow$ Trust & 0,89 & 18,48 & Significant \\
$\mathrm{H} 3$ & Brilink $\rightarrow$ Risk & 0,93 & 20,59 & Significant \\
$\mathrm{H} 4$ & Brilink $\rightarrow$ Usefullness & 0,83 & 22,38 & Significant \\
$\mathrm{H} 5$ & Brilink $\rightarrow$ Security & 0,90 & 22,63 & Significant \\
$\mathrm{H} 6$ & Brilink $\rightarrow$ Awareness & 0,81 & 22,55 & Significant \\
$\mathrm{H} 7$ & Brilink $\rightarrow$ Interest & 0,22 & 1,87 & Tidak Significant \\
$\mathrm{H} 8$ & Brilink $\rightarrow$ Desire & 0,30 & 2,86 & Significant \\
$\mathrm{H} 9$ & Awareness $\rightarrow$ Interest & 0,69 & 4,03 & Significant \\
$\mathrm{H} 10$ & Interest $\rightarrow$ Desire & 0,65 & 4,81 & Significant \\
\hline
\end{tabular}


Tabel 3. Uji hipotesis model bukan pengguna agen Brilink

\begin{tabular}{lccc}
\hline GOFI & Nilai Hasil Hitung & Nilai Standar untuk Kecocokan Baik & Kesimpulan \\
\hline RMSEA & 0,051 & $<0,08$ & Kecocokan baik \\
NFI & 0,99 & $>0,90$ & Kecocokan baik \\
NNFI & 1,00 & $>0,90$ & Kecocokan baik \\
CFI & 1,00 & $>0,90$ & Kecocokan baik \\
IFI & 0,98 & $>0,90$ & Kecocokan baik \\
Std. RMR & 0,078 & $<0,10$ & Kecocokan baik \\
GFI & 0,99 & $>0,90$ & Kecocokan baik \\
AGFI & 0,98 & $>0,90$ & Kecocokan baik \\
\hline
\end{tabular}

Hipotesis H4: Persepsi terhadap Brilink berpengaruh significant terhadap Usefullness

Hipotesis keempat menguji pengaruh persepsi terhadap Brilink terhadap Usefullness dapat menjelaskan hasil berdasarkan Tabel nilai koefisien pengaruh atau loading factor sebesar 0,89 dengan t hitung 24,51. Nilai mutlak t hitung lebih besar dari t tabel dengan alpha $5 \%$ sebesar 1,96 artinya persepsi terhadap Brilink berpengaruh significant dan positif terhadap usefullness. (Hipotesis diterima) Hal ini menunjukkan bahwa usefullness berpengaruh terhadap minat menggunakan layanan Brilink.

Hipotesis H5: Persepsi terhadap Brilink berpengaruh significant terhadap security

Hipotesis kelima menguji pengaruh persepsi terhadap Brilink terhadap security dapat menjelaskan hasil berdasarkan Tabel nilai koefisien pengaruh atau loading factor sebesar 0,91 dengan $\mathrm{t}$ hitung 19,75. Nilai mutlak $t$ hitung lebih besar dari t tabel dengan alpha 5\% sebesar 1,96 artinya persepsi terhadap Brilink berpengaruh significant dan positif terhadap security. (Hipotesis diterima) Hal ini menunjukkan bahwa security berpengaruh terhadap minat menggunakan layanan Brilink.

Hipotesis H6: Persepsi terhadap Brilink berpengaruh significant dan positif terhadap Awareness

Hipotesis keenam menguji pengaruh persepsi terhadap Brilink terhadap awareness dapat menjelaskan hasil berdasarkan Tabel nilai koefisien pengaruh atau loading factor sebesar 0,65 dengan t hitung 17,58. Nilai mutlak thitung lebih besar dari t tabel dengan alpha $5 \%$ sebesar 1,96 artinya persepsi terhadap Brilink berpengaruh significant dan positif terhadap awareness.(Hipotesis diterima) Hal ini menunjukkan bahwa persepsi terhadap Brilink dengan baik maka akan meningkatkan awareness terhadap produk BRILINK.

Hipotesis H7: Persepsi terhadap Brilink berpengaruh significant dan positif terhadap interest

Hipotesis ketujuh menguji pengaruh persepsi terhadap Brilink terhadap interest dapat menjelaskan hasil berdasarkan Tabel nilai koefisien pengaruh atau loading factor sebesar 0,22 dengan $t$ hitung 1,87 . Nilai mutlak $\mathrm{t}$ hitung lebih besar dari $\mathrm{t}$ tabel dengan alpha $10 \%$ sebesar 1,64 artinya persepsi terhadap Brilink berpengaruh significant dan positif terhadap interest. (Hipotesis diterima) Hal ini menunjukkan persepsi terhadap Brilink dengan baik maka akan meningkatkan interest terhadap produk BRILINK.

Hipotesis H8: Persepsi terhadap Brilink berpengaruh significant dan positif terhadap desire

Hipotesis kedelapan menguji pengaruh persepsi Terhadap Brilink terhadap desire dapat menjelaskan hasil berdasarkan Tabel 5 nilai koefisien pengaruh atau loading factor 0,30 dengan $\mathrm{t}$ hitung 2,86 . Nilai mutlak $\mathrm{t}$ hitung lebih besar dari t tabel dengan alpha 5\% sebesar 1,96 artinya persepsi terhadap Brilink berpengaruh significant terhadap desire (Hipotesis diterima) Hal ini menunjukkan bahwa persepsi terhadap Brilink dengan baik maka memengaruhi langsung desire produk Brilink. 
Hipotesis H9: Awareness berhubungan significant dan positif terhadap interest

Hipotesis kesembilan menguji hubungan awareness terhadap interest dapat menjelaskan hasil berdasarkan Tabel 5 nilai koefisien hubungan atau loading factor sebesar 0,65 dengan $\mathrm{t}$ hitung 4,03. Nilai mutlak $\mathrm{t}$ hitung lebih besar dari t tabel dengan alpha 5\% sebesar 1,96 artinya awareness berhubungan significant dan positif terhadap interest.(Hipotesis diterima) Hal ini menunjukkan bahwa tingkat awareness nya sudah baik maka akan meningkatkan interest terhadap produk Brilink.

Hipotesis H10: Interest berhubungan significant dan positif terhadap desire

Hipotesis kesepuluh menguji hubungan interest terhadap desire dapat menjelaskan hasil berdasarkan Tabel 5 nilai koefisien hubungan atau loading factor sebesar 0.69 dengan $\mathrm{t}$ hitung 4,81. Nilai mutlak $\mathrm{t}$ hitung lebih besar dari $\mathrm{t}$ tabel dengan alpha 5\% sebesar 1,96 artinya interest berhubungan significant dan positif terhadap interest.(Hipotesis diterima) Hal ini menunjukkan bahwa tingkat interest nya sudah baik maka akan tidak langsung meningkatkan desire terhadap produk Brilink.

Hasil hipotesis model pengguna agen Brilink disimpulkan pada Tabel 5 dan 6. Pada Tabel 6 dapat dilihat bahwa semua nilai GOFI menunjukkan kecocokan yang baik, sehingga dapat disimpulkan bahwa kecocokan data dan model adalah baik.

\section{Efektivitas Agen brilink dalam memasarkan layanan Branchless Banking BRI dengan menggunakan Metode customer response index (CRI)}

Berdasarkan perhitungan, hasil masing-masing persentase responden di tiap tahapa respon CRI dan nilai kelima tahapan respon tersebut diatas $50 \%$. Tahap respon awareness dimana tahap pertama sebanyak $89 \%$ responden menyatakan sadar dengan adanya agen brilink dilingkungan sekitar responden, sedangkan $11 \%$ menyatakan tidak sadar dengan adanya agen brilink di lingkungan sekitar responden. Tahap respon comprehend, sebanyak $87 \%$ responden yang sadar dengan agen brilink menyatakan paham dengan fungsi agen Brilink, sedangkan sisanya sebanyak $13 \%$ menyatakan tidak paham. Tahap respon interest, sebanyak $93 \%$ responden yang paham terhadap fungsi agen brilink menyatakan tertarik menggunakan agen Brilink, sedangkan sisanya sebanyak 7\% menyatakan tidak tertarik. Tahap respon Intention, sebanyak 89\% responden yang tertarik menggunakan agen brilink menyatakan minat menggunakan agen Brilink, sedangkan sisanya $11 \%$ menyatakan tidak minat. Pada tahap respon terakhir, yaitu action sebanyak $82 \%$ dari responden yang minat menggunakan agen brilink menyatakan menggunakan agen Brilink, sedangkan sisanya $18 \%$ tidak menggunakan layanan agen Brilink. Hasil persentase tiap tahap respon tersebut diproses melalui rumus perhitungan CRI sebagai berikut Tabel 7.

Tabel 3. Uji hipotesis model pengguna agen Brilink

\begin{tabular}{llccl}
\hline Hipotesis & SLF & T Hitung & Kesimpulan \\
\hline H1 & Brilink $\rightarrow$ Relative Advantage & 0,72 & 11,36 & Significant \\
H2 & Brilink $\rightarrow$ Trust & 0,94 & 18,81 & Significant \\
H3 & Brilink $\rightarrow$ Risk & 0,88 & 21,29 & Significant \\
H4 & Brilink $\rightarrow$ Usefullness & 0,89 & 24,51 & Significant \\
H5 & Brilink $\rightarrow$ Security & 0,91 & 19,75 & Significant \\
H6 & Brilink $\rightarrow$ Awareness & 0,65 & 17,58 & Significant \\
H7 & Brilink $\rightarrow$ Interest & 0,19 & 2,58 & Significant \\
H8 & Brilink $\rightarrow$ Desire & 0,22 & 2,39 & Significant \\
H9 & Brilink $\rightarrow$ Action & 0,14 & 3,04 & Significant \\
H10 & Awareness $\rightarrow$ Interest & 0,85 & 8,13 & Significant \\
H11 & Interest $\rightarrow$ Desire & 0,43 & 2,61 & Significant \\
H12 & Desire $\rightarrow$ Action & 0,79 & 8,24 & Significant \\
\hline
\end{tabular}


Tabel 6. Goodness of Fit pengguna agen Brilink

\begin{tabular}{cccc}
\hline GOFI & Nilai Hasil Hitung & Nilai Standar untuk Kecocokan Baik & Kesimpulan \\
\hline RMSEA & 0,051 & $<0,08$ & Kecocokan baik \\
NFI & 0,99 & $>0,90$ & Kecocokan baik \\
NNFI & 1,00 & $>0,90$ & Kecocokan baik \\
CFI & 1,00 & $>0,90$ & Kecocokan baik \\
IFI & 0,98 & $>0,90$ & Kecocokan baik \\
Std. RMR & 0,078 & $<0,10$ & Kecocokan baik \\
GFI & 0,99 & $>0,90$ & Kecocokan baik \\
AGFI & 0,98 & $>0,90$ & Kecocokan baik \\
\hline
\end{tabular}

Tabel 7. Persentase tiap tahap respon

\begin{tabular}{|c|c|c|}
\hline Respon & Rumus & Hasil \\
\hline Unawareness & Persentase responden yang unawareness & $11 \%$ \\
\hline No Comprehend & Awareness x No Comprehend & $89 \% \times 13 \%=12 \%$ \\
\hline No Interest & Awareness $\mathrm{x}$ Comprehend $\mathrm{x}$ No Interest & $89 \% \times 87 \% \times 93 \% \times 11 \%=8 \%$ \\
\hline No Intentions & Awareness $\mathrm{x}$ Comprehend $\mathrm{x}$ Interest $\mathrm{x}$ No Intention & $89 \% \times 87 \% \times 93 \% \times 11 \%=8 \%$ \\
\hline No Action & wareness $\mathrm{x}$ Comprehend $\mathrm{x}$ Interest $\mathrm{x}$ Intention $\mathrm{x}$ No Action & $89 \% \times 87 \%$ x $93 \%$ x $89 \% \times 18 \%=11 \%$ \\
\hline Action & Awareness $\mathrm{x}$ Comprehend $\mathrm{x}$ Interest $\mathrm{x}$ Intention $\mathrm{x}$ No Action & $89 \% \times 87 \%$ x $93 \%$ x $89 \%$ x $82 \%=53 \%$ \\
\hline
\end{tabular}

Untuk mengukur efektivitas agen Brilink, maka berdasarkan teori Customer Response Index, nilai respon harus berada di atas 50\%. Berdasarkan Tabel 8 dapat dilihat bahwa respon agen brilink berada di atas $50 \%$ di kelima tahap respon. Oleh karena itu, agen brilink dapat dikatakan efektif.

\section{Implikasi Manajerial}

Hasil penelitian dapat diketahui bahwa responden yang belum menggunakan layanan agen brilinkmemiliki persepsi pengaruh yang dominan dalam pengambilan keputusan adalah risk, security dan trust. Oleh karena itu, Bank BRI dapat memperbaiki ketiga faktor tersebut untuk dapat meningkatkan pengguna agen brilink.

Pengaruh persepsi terhadap variabel AIDA (awareness, interest, desire dan action) lebih dominan pengaruhnya secara tidak langsung dibandingkan secara langsung. Oleh karena itu, strategi yang dapat diterapkan BRI adalah dengan melakukan strategi marketing secara bertahap, yaitu membentuk awareness masyarakat, meningkatkan keinginan masyarakat untuk menggunakan layanan agen brilink, meningkatkan minat masyarakat untuk menggunakan layanan agen brilink dan yang terakhir strategi bagaimana masyarakat menggunakan layanan agen brilink. strategi pemasaran yang dapat diterapkan BRI untuk meningkatkan pengguna layanan branchless banking BRI adalah dengan menggunakan strategi marketing mix. Menurut kotler (1997) bauran pemasaran atau marketing mix adalah perangkat alat pemasaran taktis yang dapat dikendalikan produk, harga, distribusi dan promosi yang dipadukan perusahaan. Adapun strategi yang dapat diterapkan adalah sebagai berikut:

Produk

Berdasarkan hasil penelitian faktor yang dianggap penting oleh bukan pengguna agen brilinkadalah risk, security dan trust, sehingga Bank BRI memperbaiki ketiga faktor tersebut untuk meningkatkan pengguna agen brilink. Berikut adalah strategi yang dapat diterapkan oleh Bank BRI.

a. Risk

Risiko merupakan faktor persepsi yang paling dianggap penting oleh bukan pengguna agen brilink, oleh karena itu BRI dapat melakukan mitigasi risiko dalam pelayanan branchless banking salah satunya adalah bekerjasama dengan asuransi kerugian, jika terjadi risiko fraud yang dilakukan oleh agen brilink, nasabah akan mendapatkan garansi penjaminan dari asuransi kerugian. 
Tabel 8. Nilai CRI Agen Brilink

\begin{tabular}{lcc}
\hline $\begin{array}{l}\text { Customer } \\
\text { Response }\end{array}$ & $\begin{array}{c}\text { Nilai CRI } \\
\text { Minimal }\end{array}$ & Nilai Hasil CRI \\
\hline Awareness & $50 \%$ & $89 \%$ \\
Comprehend & $50 \%$ & $87 \%$ \\
Interest & $50 \%$ & $93 \%$ \\
Intentions & $50 \%$ & $89 \%$ \\
Action & $50 \%$ & $53 \%$ \\
\hline
\end{tabular}

\section{b. Security}

Security sebagai faktor kedua yang dianggap penting bagi bukan pengguna agen brilink. Oleh karena itu, Bank BRI dapat memilah lokasi agen brilinkyang ada. Lokasi agen brilinkyang dekat dengan keramaian akan membuat nasabah BRI merasa nyaman ketikan bertransaksi.

\section{c. Trust}

Faktor trust dapat ditingkatkan dengan dilakukannya edukasi dan sosialisasi mengenai agen brilinkoleh Bank BRI. Bank BRI dapat melakukan edukasi dan sosialisasi dengan cara: Menyampaikan layanan branchless banking pada saat gathering nasabah BRI; Menyampaikan layanan branchless banking pada nasabah walk in customer yang datang ke Kantor Cabang; Menyampaikan kepada nasabah alamat dan kontak Agen brilink yang resmi bekerjasama dengan BRI.

\section{Harga}

Strategi penetapan harga dapat dilakukan BRI dengan cara menetapkan harga transaksi yang sama dengan Unit Kerja BRI (Kantor Cabang) sehingga tidak terdapat perbedaan ketika nasabah bertransaksi di Kantor Cabang dan di agen brilink.

\section{Distribusi/Place}

Berdasarkan hasil survei nasabah BRI yang bukan pengguna layanan agen brilink didominasi oleh nasabah dengan pengeluaran $>$ Rp5-7,5 Juta sebesar 41\% yang dimana nasabah tersebut merupakan nasabah golongan menengah. Bank BRI perlu mempertimbangkan standarisasi tempat yang bisa digunakan dalam melayani agen brilink. Salah satunya adalah tersedianya lahan parkir dan counter pelayanan agen brilink
Promosi

Berdasarkan penelitian variabel persepsi lebih dominan pengaruhnya secara tidak langsung terhadap variabel AIDA dibandingkan pengaruhnya secara langsung, oleh karena itu strategi yang dapat dilakukan adalah dengan cara membentuk persepsi masyarakat secara bertahap: Membentuk awareness masyarakat (Pembentukan awareness dapat dilakukan dengan promosi melalui media cetak ataupun elektronik, selain itu spanduk dan banner yang menarik di lokasi agen brilinkjuga dapat membentuk awareness masyarakat); Membentuk interest masyarakat (pembentukan interest masyarakat dapat dilakukan dengan sosialisasi dan edukasi kepada masyarakat mengenai kemudahan bertransaksi melalui agen brilink); Membentuk minat masyarakat (pembentukan minat masyarakat dapat dilakukan dengan promosi yang menonjolkan manfaat bertransaksi melalui agen brilink); Melakukan akuisisi penjualan (akuisisi penjualan dapat dilakukan dengan cara memberikan gimmick kepada masyarakat yang ingin menggunakan layanan agen brilink).

\section{KESIMPULAN DAN SARAN}

\section{Kesimpulan}

Faktor terpenting bagi pengguna agen brilink yang memengaruhi keputusan penggunaan agen brilink adalah kepercayaan, keamanan, manfaat, risiko dan relative advantage. Sedangkan pada Model penelitian bukan pengguna agen brilink: faktor terpenting bagi bukan pengguna agen brilink yang memengaruhi keputusan penggunaan agen brilink adalah risiko, keamanan, kepercayaan, relative advantage, dan manfaat.

Pengaruh variabel persepsi lebih dominan berpengaruh tidak langsung terhadap variabel AIDA (awarness, interest, desire dan action) dibandingkan pengaruh secara langsung. Berdasarkan hasil customer response index agen brilink dapat dikatakan. efektif dalam membentuk awareness, interest, desire hingga action dengan nilai customer response di setiap tahapan lebih besar dari CRI minimum, yaitu $50 \%$.

\section{Saran}

Bank yang menggunakan channel Agen Brilink (Agen Branchless Banking) sebagai kepanjangtanganan 
layanan perbankan ke nasabah yang berdomisili jauh dari Bank, tentunya harus memperhatikan faktor-faktor yang ada dalam penelitian ini, yaitu faktor kepercayaan nasabah, faktor keamanan bertransaksi, faktor manfaat, faktor risiko dan faktor relative advantage. Hal ini tentunya dapat didukung dengan adanya standarisasi bagi agen brilink yang mencakup faktor-faktor tersebut. Dengan adanya standarisasi akan membuat nasabah lebih yakin untuk dapat menggunakan layanan Agen Brilink.

\section{DAFTAR PUSTAKA}

Abdul R, Zainul A, Wilopo. 2012. Pengaruh Penerapan AIDA (Attention, Interest, Desire, action) Terhadap Keputusan Pembelian. Malang:Universitas Brawijaya.

Aiwan TS. 3013. Efektifitas Pesan Iklan Televisi Tresemme Menggunakan Metode Customer Response Index (CRI) Pada Perempuan di Surabaya. Jurnal E-Komunikasi I(2).

Amijaya GR. 2010.Pengaruh Persepsi Teknologi Informasi, Kemudahan, Risiko dan Fitur Layanan terhadap Minat Ulang Nasabah Bank Dalam Menggunakan Internet Banking, [Skripsi]. Semarang: Universitas Dipenogoro.

Ayuningtyas V. 2014. Analisis Pengaruh Kompetensi

Tenaga Penjual, Daya Tarik Promosi dan Citra Perusahaan Terhadap Keputusan Pembelian Produk Asuransi Jiwa. Semarang : Program Magister Manajemen Universitas Dipenogoro.

Baskara IP, Guruh TH.2015. Analisis Pengaruh Kepercayaan, Kemanan, Kualitas Pelayanan dan Persepsi Akan Risiko terhadap Keputusan Pembelian Melalui Situs Jejaring Sosial. Semarang : Universitas Dian Nuswantoro.

Budiawan R, Satria A, Simanjuntak M. 2017. The quasi experimental study of the influence of advertising creativity and exposure intensity toward purchasing action with AIDA approach. Independent Journal of Managemenr \& Production 8(1):378-394. https://doi. org/10.14807/ijmp.v8i2.526.

Damayanti D. 2013. Financial Inclusion: Sebatas Kepentingan Bank. Jakarta : Sinar Harapan.

Darmadi D, Anton WW, Hermawan S. 2003.Inovasi Pasar Dengan Iklan Yang Efektif: Strategi, Program dan Teknik Pengukuran. Jakarta : PT Gramedia Pustaka Utama.

Dewi IAPM.2016.Efektifitas iklan dengan analisa
AIDA studi pada penguna sepeda motor merek Yamaha di Singaraja. Jurnal Program Studi Pendidikan Ekonomi 7(1):378-394.

Ernestivita G. 2016. Analisis efektifitas tagline iklan televisi minuman ringan teh botol sosro versi "apapun makanannya minumannya the botol sosro" dengan menggunakan customer response index.Jurnal Riset Ekonomi dan Bisnis 11(1):111.

Fazri A. Mengukur jumlah paparan TVC yang efektif biaya untuk menimbulkan dampak attention, interest, desire dan action pada konsumen di Kota Jambi. Jurnal Manajemen Pemasaran Modern 1(1):1-10.

Ferdinand A. 2002.Structural Equation Modelling Dalam Pemelitian Manajemen. Semarang: FE Undip

Golob TF. 2003. Structural equation modeling for travel behavior research. Transportation Research Part B: Methodological 37(1): 1-25. https://doi. org/10.1016/S0191-2615(01)00046-7.

Hotman M, Hidayat.2016. Pengaruh suasana toko dan lokasi terhadap minat beli ulang konsumen di UD Nasyila Toys Simpang SKPD. Jurnal Management dan Ekonomi 1(1) : 1-10.

Johar DS, Kumadji S, Mawardi MK.2015. Pengaruh AIDA terhadap efektifitas iklan online. Jurnal Administrasi dan Bisnis 26(1): 1-10.

Kumitirasih ANQ. 2015. Tanggung Jawab Agen Layanan Keuangan Tanpa Kantor Dalam Rangka Keuangan Inklusif Terhadap Rahasia Bank. Jurnal Ilmiah Fakultas Hukum Universitas Brawijaya.

Kotler P. 2003. Marketing Management, 11th edition. New Jersey: Prentice Hall.

Noerkaisar N, Saharjo B, Yuliati LN.2016. The adoption stages of mobile navigation technology waze application as Jakarta trafic jam solution. Independent Journal of Management \& Production 7(1): 914-925. https://doi. org/10.14807/ijmp.v7i3.447.

Patricia P. 2016. Efektivitas Iklan TV Telkomsel 4G LTE Versi \#menjadiyangterbaik Bagi Relawan Bencana Pada Masyarakat Surabaya. Jurnal E-Komunikasi 4(1).

Purwati, Yenny, Rosali F, Paskah I. 2014. Strategi Peningkatan Kemampuan Adopsi Teknologi Branchless Banking Untuk Memperluas Inklusi Keuangan di Masyarakat Pedesaan. Semarang : Seminar National dan Call for Paper Hlm 204211. 
Rahab. 2009. Hubungan Antara Karakteristik Teknologi Dengan Kemungkinan Usaha Kecil Untuk Mengadopsi TI. Jurnal Bisnis dan Ekonomi 111-125.

Riska S, Fuad A, Imam S. 2014. Pengaruh Green Marketing, Pengetahuan dan Minat Membeli Terhadap Keputusan Pembelian. Jurnal Management Teknologi 13(2):201-218. https:// doi.org/10.12695/jmt.2014.13.2.6.

Ragil BW. 2015.Pengaruh Sales Promotion Girl Smartphone Samsung Terhadap Keputusan Pembelian (Studi Konsumen Smartphone Samsung Indonesia Tahun 2015). Bandung: Universitas Telkom.

Rofiq A, Zainul A, Wilopo. 2012. Pengaruh Penerapan AIDA Terhadap Keputusan Pembelian. Malang: Jurnal Fakultas Ilmu Administrasi Universitas Brawijaya.

Sakti TP. 2014. Pengaruh Tahapan AIDA Pada Iklan Rokok Terhadap Keputusan Pembelian Konsumen. Jember: Fakultas Ilmu Sosial dan Ilmu Politik Universitas Jember.

Setiawan MA. 2014. Analisis Keterkaitan Inklusi Keuangan Terhadap Perilaku Keuangan Personal Masyarakat Di Wilayah Kota dan Kabupaten Provinsi Jawa Timur. Malang : Fakultas Ekonomi dan Bisnis, Universitas Brawijaya.x

Setyani I.2013. Model Inklusi Keuangan Pada UMKM

Berbasis Pedesaan. Journal of Economics and Policy.

Slameto.2010.Belajar dan Faktor-Faktor Yang Mempengaruhi. Jakarta: Rineka Cipta.

Steelyana E. 2013. Perempuan dan Perbankan : Sebuah

Tinjauan Tentang Peran Inklusi Keuangan

Terhadap Pengusaha UMKM Perempuan di
Indonesia. Journal The Winners 14(2): 95-103. https://doi.org/10.21512/tw.v14i2.649.

Sugiarto A. 2014.Strategi Nasional Literasi Keuangan. Diambil dari materi seminar OJK. (Online). http://ikatanbankir.com/uploads/seminar/LKDFinal8May2014.pptx [8 Juli 2017].

Suhir M, Imam S, Riyadi.2015. Pengaruh Persepsi Risiko, Kemudahan dan Manfaat Terhadap Keputusan Pembelian Secara Online. Jurnal Administrasi dan Bisnis 8(1).

Tjahyono PP. 2016. Efektivitas Iklan Televisi Telkomsel 4G LTE Versi \#menjadiyangterbaik Bagi Relawan Bencana Pada Masyarakat Surabaya: Jurnal Ekonomi dan Bisnis XV(1).

Trenggono PS. 2014. Pengaruh Tahapa AIDA Pada Iklan Rokok Terhadap Keputusan Pembelian Konsumen. Jember: Universitas Jember.

Otoritas Jasa Keuangan. 2019. Statistik Perbankan Indonesia Edisi November 2019. [internet] [diunduh pada : 2020 Februari 09] tersedia pada http://www.ojk.go.id/id/kanal/perbankan/ data-dan-statistik/statistik perbankan-indonesia/ Pages/Statistik-Perbankan-Indonesia--November-2019.aspx[8 Juli 2017].

Utama SS, Andadari RK, Matrutty ES. Efektivitas Iklan Televisi Partai Gerindra Berdasarkan Metode Customer Response Index (CRI) di Salatiga. Jurnal Ekonomi dan Bisnis XV(1).

Wahid,Fathul,Lizda I. 2007.Adopsi Teknologi Informasi Oleh Usaha Kecil dan Menengah di Indonesia. Yogyakarta: Universitas Islam Indonesia.

Yuwono RF. 2004. Efektivitas Iklan Jayanata di Surat Kabar Jawa Pos terhadap Masyarakat Surabaya. Jurnal E-Komunikasi Program Studi Ilmu Komunikasi Universitas Petra Surabaya 2(1). 